\title{
Rain-Flow Modeling Using a Multi-Layer Artificial Neural Network on the Watershed of the Cavally River (Côte d'Ivoire)
}

\author{
Brou Loukou Alexis ${ }^{*}$, Kouassi Kouakou Lazare', Konan Kouakou Séraphin', \\ Kouadio Zilé Alex ${ }^{1}$, Konan Koffi Félix ${ }^{1}$, Kamagate Bamory ${ }^{2}$ \\ ${ }^{1}$ Université Jean Lorougnon Guédé, Daloa, Côte d'Ivoire \\ ${ }^{2}$ Université Nangui-Abrogoua, Abidjan, Côte d'Ivoire \\ Email: ^broualexis30@gmail.com
}

How to cite this paper: Alexis, B.L., Lazare, K.K., Séraphin, K.K., Alex, K.Z., Félix, K.K. and Bamory, K. (2017) Rain-Flow Modeling Using a Multi-Layer Artificial Neural Network on the Watershed of the Cavally River (Côte d'Ivoire). Journal of Water Resource and Protection, 9, 14031413.

https://doi.org/10.4236/jwarp.2017.912090

Received: September 15, 2017

Accepted: November 25, 2017

Published: November 28, 2017

Copyright $\odot 2017$ by authors and Scientific Research Publishing Inc. This work is licensed under the Creative Commons Attribution International License (CC BY 4.0).

http://creativecommons.org/licenses/by/4.0/

\begin{abstract}
Water resources management is nowadays a significant stake for the world. However, missing or bad quality of the hydro-climatic historical data available of the studied area makes sometimes hydrological studies difficult. Generally, conceptual rain-flow models are designed to bring an appropriate answer with the correction of gaps and prediction of the flows. Historical hydro-climatic data of the Ity station, located on Cavally River, contain gaps which must be bridged. This study aims to establish a rainfall-runoff model through artificial neural networks for filling the gaps into the flow data series of the hydrometric station of Ity on the watershed of Cavally River. A multi-layer perceptron of feed forwards with two entries (monthly average rain and evapotranspiration) and an exit (flows) was established with flow evapotranspiration data. Comparison of the criteria of performance of the various architectures of the neural network model showed that architecture 2-3-1 gives best results. This architecture provides Nash coefficients of $75.79 \%$ and correlation linear coefficient of $95.64 \%$ for the calibration and Nash coefficients of $73.32 \%$ and correlation linear coefficient of $98.33 \%$ for the validation. The correlations between simulated flows and observed flows are strong. The correlation coefficients are $83.89 \%$ and $83.08 \%$ respectively for the calibration and validation.
\end{abstract}

\section{Keywords}

Rain-Flow Modeling, Artificial Neural Network, Cavally River, Côte d'Ivoire

\section{Introduction}

The management of water resources constitutes a major stake for most of the 
countries in the world. For instance, the prevision of future hydrologic conditions is of capital importance in the planning and the management of water resources [1]. To predict flows, knowledge of the data on flows and/or past and present rains is necessary. However, the absence or the poor quality (gaps, measuring mistakes...) of hydro climatic data makes these hydrological studies difficult. Therefore filling of gaps is necessary before any use. Correlation methods between stations of same areas for filling gaps are often limited by the weak density of stations on the watersheds. The rain-flow model could bring an adequate solution to fill the gaps in the series of flow and rain data [2]. Indeed, the simulation of flow is one solution in the filling of gaps in the series of data, the reconstitution of historical flows. Owing to the difficulties to state nonlinear models, recent attempts resorts to artificial neurons networks (ANN) for the hydrological modeling of complex watersheds. Since early 1990s, artificial neurons networks have been used successfully in domains linked to hydrology such as the modeling of rain-flow, quality of water, strategy of water management, prevision of precipitation, hydrological chronological series [3], the estimation of non-measured floods [4], the prevision of typhoon-rain [5], the estimation of the flow of a river [6], for ameliorating the modeling rain-flow based on rainy events [7], the predictions of the chronological series of the height of rain [8], the modeling of the relation rain-flow [2]. Plus the distribution of Markov range for the probable distribution of rain in the lower watershed of the Bia [9]. Artificial neurons networks (ANNs) use dependent data. They do not impose any functional relation between independent and dependent variables in so far as this relation is terminated by the data in the learning process (or calibration) [10]. Mathematically, an ANN can be considered as universal approximation. For its capacity to learn and to generalize "the knowledge" of pairs of sufficient data artificial neurons networks can solve complex problems on big scale such as the recognition of forms, classification, association, check, nonlinear modeling and other problems [11]. This article aims to establish a model of rain-flow of the Cavally watershed of the hydrometric station of Ity in order to determine the flow and to fill the detected gaps in the series of the recorded historical data.

\section{Material and Methods}

\subsection{Presentation of the Study Area}

The Cavally River is a lower cross border watershed between Guinea, Ivory Coast and Liberia. Located in the west of Ivory Coast, the Cavally River begins in Guinea, in the North of Mount Nimba with more than 1000 meters as approximate altitude (Figure 1). $700 \mathrm{~km}$ long, its riverbed constitutes the border between Liberia and Ivory Coast from its middle way (at the South of Toulépleu) on about $330 \mathrm{~km}$. The lower watershed covers a complete area of 28,800 Sq Km at Tate hydrometric station located at $60 \mathrm{~km}$ from the mouth. Côte d'Ivoire doesn't possess but about 15,000 Sq km of watershed [12]. In the framework of this study, the chosen outlet is the hydrometric station of Floleu located at 

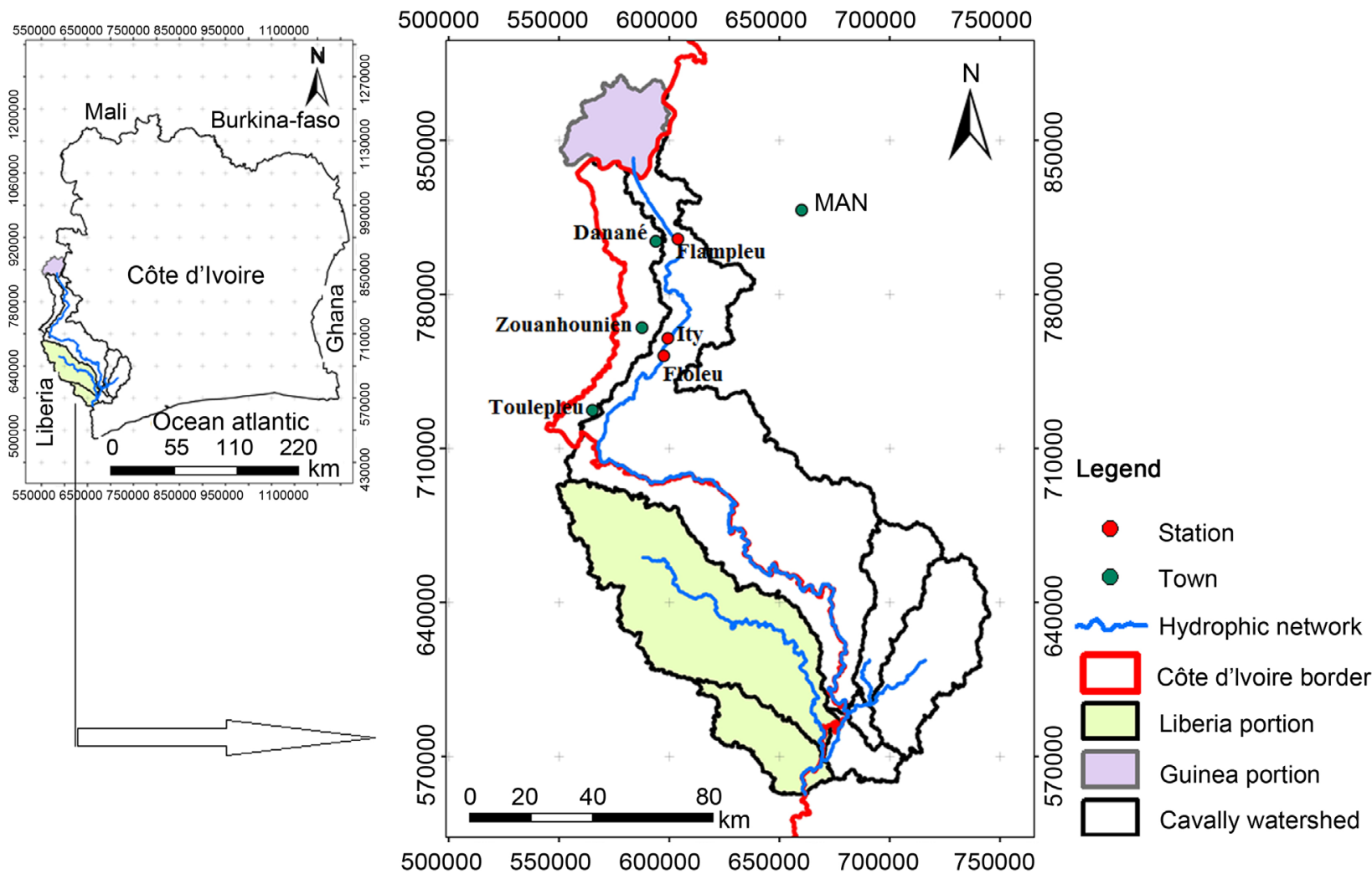

Figure 1. Study area of sub-watershed of Cavally River.

downstream of the Ity station in the Zouan-Hounien region. The low watershed has got an area of $3647.53 \mathrm{Sq} \mathrm{km}$ (Figure 1). The region of Zouan-Hounien is located in the mountain region of Côte d'Ivoire; its relief is hilly. Zouan-Hounien is located in the forest area and its climate is the mountain climate with two seasons: one rainy season from May to October and one dry season from November to March. The annual average temperature is $25.6^{\circ} \mathrm{C}$. The annual average precipitation is $186 \mathrm{~mm}$. The driest month is January with a precipitation of $15 \mathrm{~mm}$. The most important precipitations are recorded in September and they are 357 $\mathrm{mm}$ in average.

\subsection{Data Acquisition and Analysis}

The data used in the framework of this study are issued by three (3) hydrometric stations (Flampleu, Ity and Toulépleu) providing data about rain and temperature on the exploitation site of the Mining company of Ity (SM1). The daily data about flows are provided by the general office of infrastructures and human hydraulic (DGIHH) under the authority of the Ministry of Economic Infrastructures of the Republic of Côte d'Ivoire, whereas the data about monthly rains were acquired via the Company of development and Airport and Maritime exploitation (SODEXAM). To obtain the same pace of time like monthly rains, daily flows were transformed in monthly flows. These data cover the period from 1980 to 2001 for flows and from 1990 to 2007 for hydro-climate data. In 
order to permit the model to correctly simulate the provided data, a period of common basis was chosen by taking into account the quality of data that is to say with less gaps over a continuous period from August 1990 to December 2001. The potential monthly evapotranspiration was calculated by the formula of THORNTHWAITE (1994). The characteristic values are recorded in Table 1.

\subsection{Rain-Flow Modeling Method by Neural Network}

The setting of an artificial neural network constitutes four (4) steps: data search, pre-treatment of these data, learning and evaluation of the model. In this study, a perception of feed forwards retro propagation model with two layers, one hidden layer and one layer of exit was constituted (Figure 2).

To set neural network model, the data about average rain, ETP and flows on monthly pace on a continuous period from August 1990 to December 2001 were used. These data are firstly normed between the interval $[0 ; 1]$ in order to permit an efficient treatment accepted by the in and out functions of the network [13]. The functions used for the normalization of the entry vector are given by the following relation [14].

$$
X_{N}=\left(X-X_{\min }\right) \frac{X_{N \max }-X_{N \min }}{X_{\text {max }}-X_{\min }}+X_{N \text { min }}
$$

$X_{N}=$ normalized value corresponding to the elements of the entries vector (Rain, ETP), $X=$ Real value of an element of the entries vector, $X_{\min }=$ minimum

Table 1. Hydro-climatic and flow data characteristics of Ity region.

\begin{tabular}{ccccc}
\hline & Flow $\left(\mathrm{m}^{3} / \mathrm{s}\right)$ & Rain $(\mathrm{mm})$ & Temperature $\left({ }^{\circ} \mathrm{C}\right)$ & ETP $(\mathrm{mm})$ \\
\hline Maximum & 327.27 & 531.70 & 28 & 141.42 \\
Average & 143.69 & 151.37 & 25.76 & 85.9 \\
Minimum & 76.52 & 0.0 & 24 & 62.90 \\
STDEVA & 59.28 & 109.51 & 1.03 & 14.10 \\
\hline
\end{tabular}

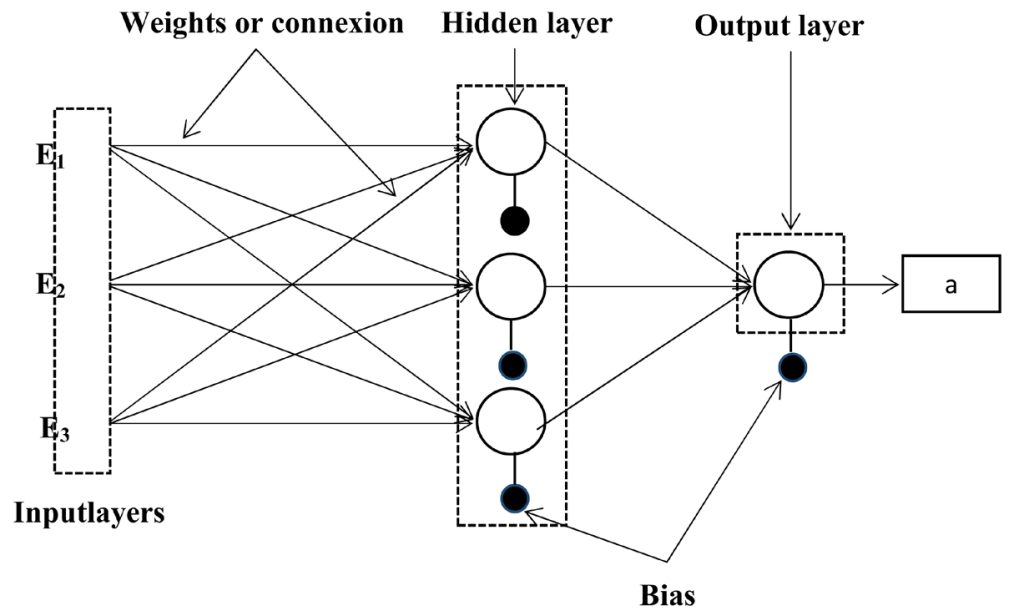

Figure 2. Multi-layers neuron network model. 
value of an element of the entries vector, $X_{\max }=$ maximum value of an element of the entries vector, $X_{N \min }=$ minimum value of the normalization vector $[0 ; 1]$ equal $0, X_{N \max }=$ maximum value of the normalization vector $[0 ; 1]$ equal 1.

These data are then subdivided in three (3) sub-sets: calibration, test and validation done respectively according to proportions of $50 \%, 30 \%$ and $20 \%$ equivalent respectively to 5; 3 and 2 years (Figure 3). A multi-layer perception of feed forwards model two (2) entries (average rain and ETP) and one exit (flows) with an architecture varying from one neuron to five hidden neurons. The network so constituted is trained in supervised way by an algorithm of second order (Levenberg Marquardt) according to retro propagation. In addition, to make converge rapidly the model, the weights and initial bias were fixed to 0,1 .

The programming was done under Matlab software R 2014 version. The artificial neural network developed in this study has the following characteristic:

- Mistake criterium: quadratic mistake.

- Activation function: Sigmoid function bounded from 0 to 1;

- Initial weights: 0,1 .

- Initial bias: 0.1;

- Number of iterations: 500.

The model is assessed with two (2) digital criteria (Nash coefficient and correlation coefficient) and graphic criteria (hydrograph of the observed and simulated of flows).

\subsubsection{Nash Coefficient}

In order to quantify the precision of the simulation and reliability of the model, Nash coefficient is applied on the obtained results [15]. Nash coefficient is then expressed by the following relation:

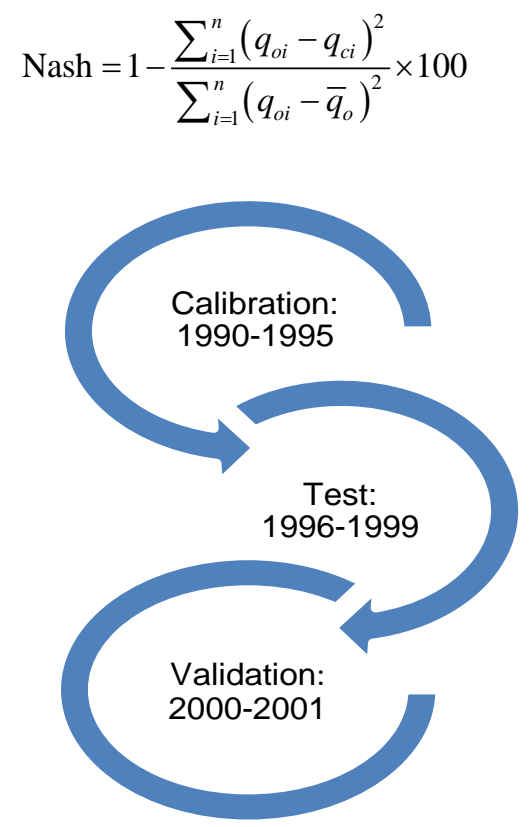

Figure 3. Process of data distribution into artificial neuron network model. 


\subsubsection{Correlation Coefficient}

Noted $R$, the correlation coefficient on Pearson coefficient is the square root of the determination coefficient given by the relation:

$$
R=\frac{\sum_{i}\left(q_{o i}-\bar{q}_{o}\right)\left(q_{c i}-\bar{q}_{c}\right)}{\sqrt{\sum_{i}\left(q_{o i}-\bar{q}_{o}\right)^{2} \times \sum_{i}\left(q_{c i}-\bar{q}_{c}\right)^{2}}}
$$

In these two expressions, $n$ represents the height of the sequence, $q_{o i}$ represents the observed flow for calculated flow for the pace time $i$ in $\mathrm{m}^{3} / \mathrm{s} ; q_{c>}$ is the calculated flow for the pace time $i$ in $\mathrm{m}^{3} / \mathrm{s} ; \bar{q}_{o}$ is the observed average flow in $\mathrm{m}^{3} / \mathrm{s}$.

\section{Results and Discussion}

In modeling by neural network, to avoid an over learning (modeling of the raw), the obtained results are starting from the reserved data for learning must be validated on a new set of data. Table 2 presents the criteria of estimation of the performance of the model in accordance with four [4] architectures (2-3-1; $2-4-1 ; 2-5-1$ and 2-6-1) at the calibration and validation levels.

Observing this table, all the architectures given better performance criteria in accordance with the criteria of evaluation of the performance of a model, which must be higher than $60 \%$ for the Nash criteria and $80 \%$ for the correlation coefficient. However in the modeling of artificial neural network more the quantity of hidden layer is higher more the model becomes complex and unstable. To reduce this complexity of the model, it is necessary to choose the models which have fewer layers. There by the most appropriate model in the framework of this study is architecture model 2-3-1. So, the results of calibration and validation will be presented this way. Figure 4 presents respectively the hydrographs and the correlation between the observed and the simulated flows by model 2-3-1 at the calibration level.

Although there are some gaps, model simulates better the flows. Indeed, gaps are noticed at the level of hydrographs of the observed and the simulated flows at the level of the calibration step of the model (Figure 4) but, Nash coefficient (75.79\%) is for superior to $60 \%$ value from which a model can be considered efficient and stable. The linear correlation between the observed and the simulated flow sis strong with a correlation coefficient of $95.64 \%$ at the calibration level as

Table 2. Criteria of evaluation of artificial neural network the model performance for different structures.

\begin{tabular}{ccccccc}
\hline & \multicolumn{5}{c}{ Structures of model } \\
\cline { 3 - 7 } & & & $2-3-1$ & $2-4-1$ & $2-5-1$ & $2-6-1$ \\
\hline \multirow{3}{*}{$\begin{array}{c}\text { Criteria of } \\
\text { valuation }\end{array}$} & \multirow{2}{*}{ NASH } & Calibration & 75.79 & 74.18 & 73.68 & 74.21 \\
& & Validation & 73.33 & 74.64 & 74.02 & 73.75 \\
& Correlation & Calibration & $\mathbf{9 5 . 6 4}$ & 95.81 & 97.43 & 95.96 \\
& coefficient & Validation & $\mathbf{9 8 . 3 3}$ & 98.4 & 96.93 & 98.86 \\
\hline
\end{tabular}



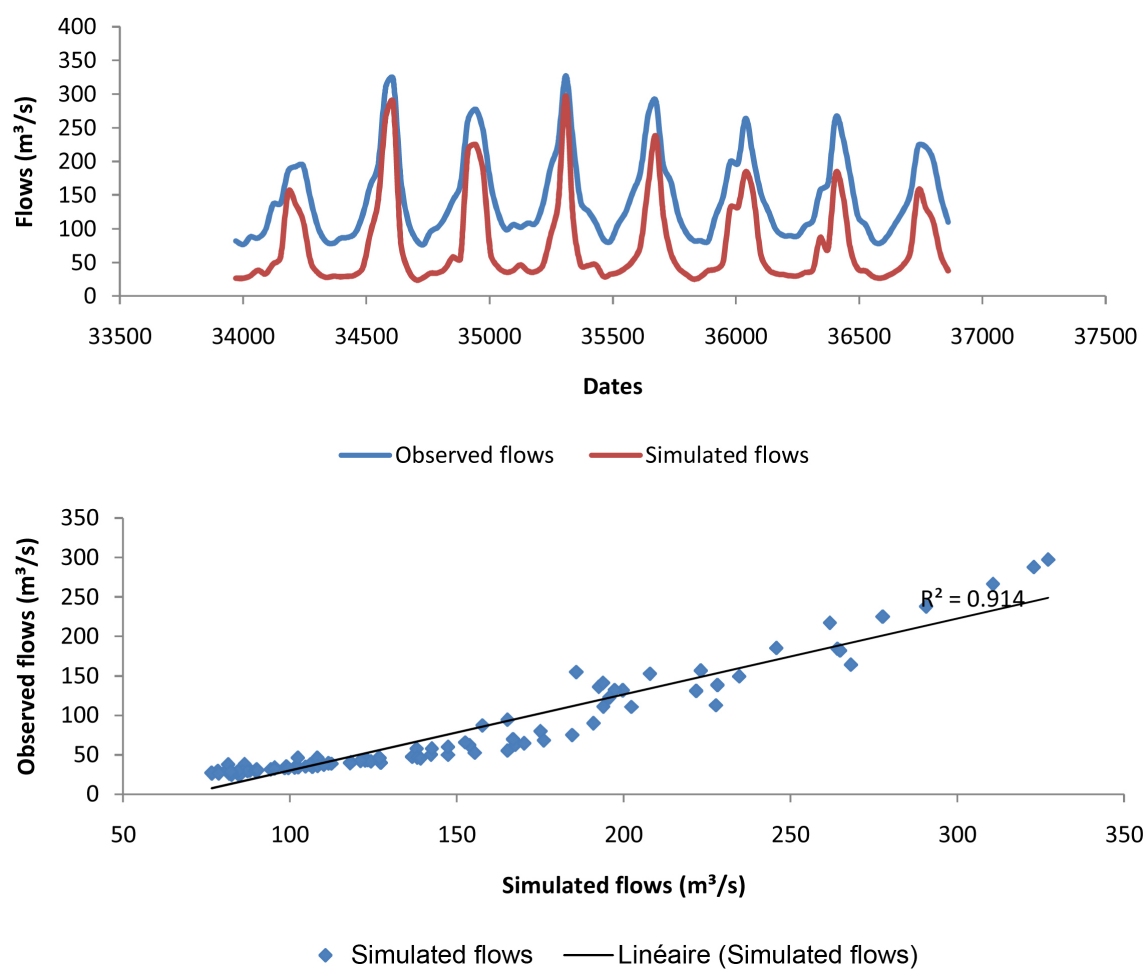

Figure 4. Hydrographs and graphical representation of the correlation between observed and simulated flow rates for the 2-3-1 structure of ANN model at the calibration level.

presented in Figure 4. Figure 5 presents respectively flow hydrographs and the correlation between the observed and simulated flows by model 2-3-1 at the level of the validation model.

This step of validation model 2-3-1 presents Nash coefficients and respective linear correlation of $73.32 \%$ and $98.33 \%$. These two criteria (Criterion of Nash and coefficient of correlation) allow appreciating the reliability and the stability of the artificial neurons network model. In effect, when the criterion of Nash is superior to $60 \%$ and the coefficient of linear correlation is superior to $80 \%$, the model can be considered efficient. So, the analysis of the results shows that for three (3) hidden neurons, the model presents good performance criteria.

The Table 3 summarizes performance criteria for the Artificial Neural Network model 2-3-1.

However, the tasks done [2] at the station of Bianouan on the river Bia revealed that the model with hidden neurons also gives interesting results with some criteria of Nash of $60.37 \%$ and the coefficient of correlation of $83.08 \%$ for validation. This difference in results could be explained by the density of the series of data for modeling which used a 26 year series of data whereas in this study the series of data is 10 years old. The model of neural network developed with the data of average rain, ETP calculated by the THORNTHWAITE method and the method of flow over the period from 1990 to 2001 gave good results with the architecture. Therefore, three (3) hidden neurons are necessary to well simulate flows at hydrometric station of Ity starting from two (2) entries (average 

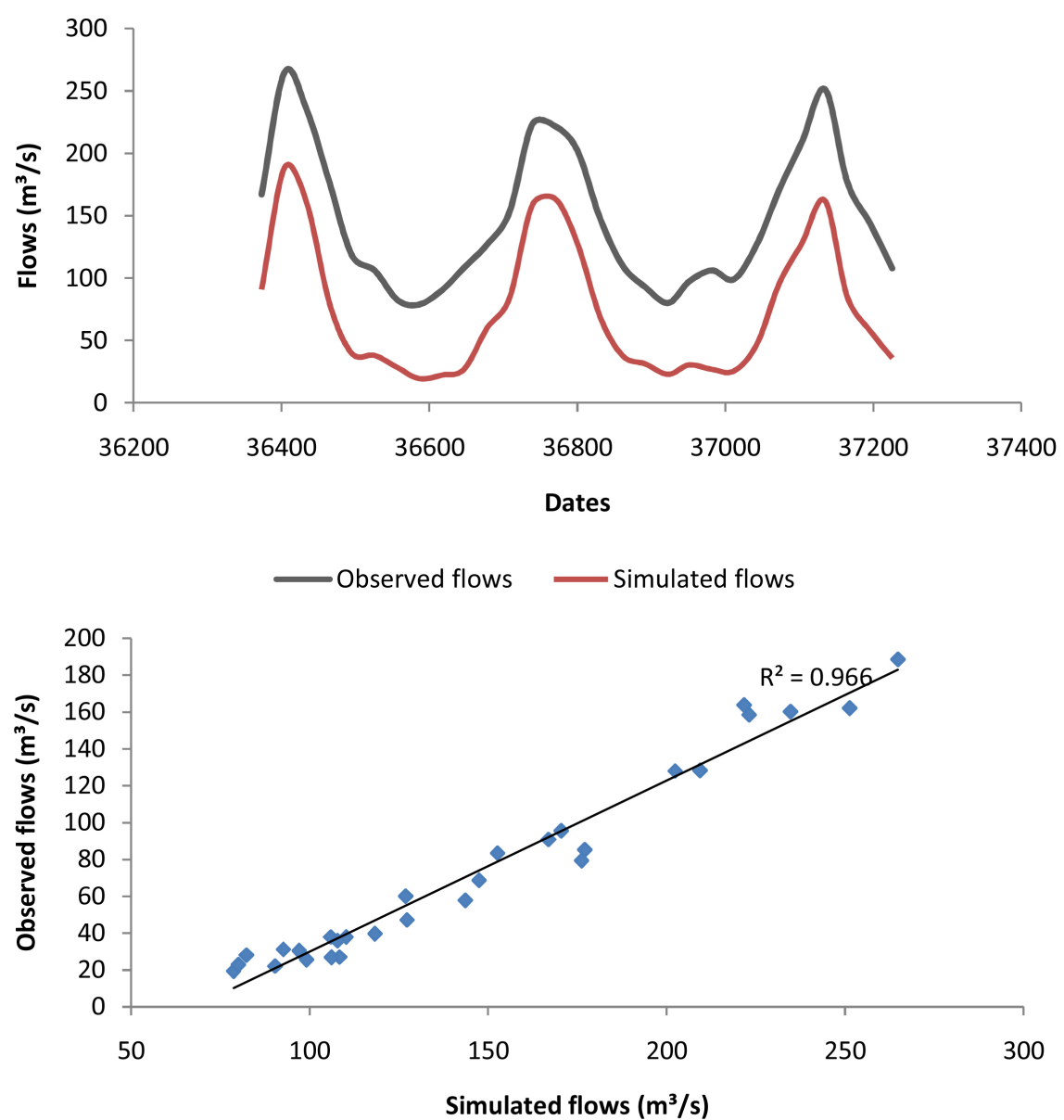

- Simulated flows Linéaire (Simulated flows)

Figure 5. Hydrographs and graphical representation of the correlation between Observed (Qobs) and simulated (Qcal) flow rates for the 2-3-1 structure of ANN model at the validation level.

Table 3. Performance criteria for the artificial neural network model 2-3-1.

\begin{tabular}{ccc}
\hline Criteria of evaluation & Calibration & validation \\
\hline Criterion of Nash & $75.79 \%$ & $73.32 \%$ \\
Coefficient of correlation & $95.64 \%$ & $98.33 \%$
\end{tabular}

rain and ETP calculated by the THORNTHWAITE). The tasks of [16] cited by [2] sunstroke and temperature and used with the average rain could simulate better the flows [17].

However, some gaps are noticed between the observed flows and the simulated flows by architecture 2-3-1 of the artificial neurons networks at the artificial neurons networks at the validation level. These differences can be explained by the fact that the artificial neurons networks are models which are influenced by the number of variables of entries model, the length of the series of data for the tuning and the quality of data. In fact, although the two variables of entries (average rain and ETP) well-simulate the flows at the station of Ity, the flows at 
this station are not only influence drain and ETP. According to [18]; [19] and [2], vegetation, the level of the stream, the capacity of retention of water of the soil, relief and the others losses are factors which influence the transformation of rain in flow. Consequently, [20] it is proven that by increasing the number of variables of entries of a model of artificial neurons network by one (1) to three (3) entries, the performance of the model improves considerably. The results obtained in this study (model 2-3-1) compared with those obtained (model 2-4-1) by [2] give approximately similar results. Since then, we could say that the number of neurons does not influence a lot the performance of the model to transform the rain in flow when comparatively with the quantity of data, the number entries data in the network.

\section{Conclusion}

This study allowed establishing a model of rain-flow thank to the artificial neuron network (multi-layer perception a feed forwards model) which is used to feel the gaps in the series of flows of the hydrometric station of Ity on the Cavally River. The results obtained through this model of artificial neuron network show that architecture 2-5-1 gives satisfactory results with $73.68 \%$ as Nash criterion at the tuning level and simulated flows of $97.43 \%$, at test phase level a Nash criterion of $77.95 \%$, and a very strong correlation of $98.42 \%$, and the validation level a Nash criterion of $66.41 \%$ for a correlation between observed flows and simulated flows of $96.93 \%$. This model will help in addition to the filling of gaps at the level rain data and flows, the evaluation of the impacts of anthropic activities on the down watershed of the Cavally River.

\section{References}

[1] Araghinejad, S., Azmi, M. and Kholghi, M. (2011) Application of Artificial Neural Network Ensembles in Probabilistic Hydrological Forecasting. Journal of Hydrolo$g y$, 407, 94-104. https://doi.org/10.1016/j.jhydrol.2011.07.011

[2] Kouassi, K.L., Kouassi, K.M., Konan, K.S., Meledje, N.H., Koffi, Y.B. and Biémi, J. (2013) Modélisation Pluie-Débit à L'aide des Réseaux de Neurones Artificiels sur le Bassin Versant Transfrontalier de la Bia (Côte D’ivoire-Ghana) [Rainfall-Flow Modeling Using Artificial Neural Networks on the Transboundary Basin of the Bia (Ivory Coast-Ghana).]. European Journal of Scientific Research, 109, 133-140.

[3] ASCE (2000) Artificial Neural Networks in Hydrology. I: Preliminary Concepts. Journal of Hydrologic Engineering, 5, 115-123. https://doi.org/10.1061/(ASCE)1084-0699(2000)5:2(115)

[4] Dawson, C.W., Abrahart, R.J., Shamseldin, A.Y. and Wilby, R.L. (2006) Flood Estimation at Ungauged Sites Using Artificial Neural Networks. Journal of Hydrology, 319, 391-409. https://doi.org/10.1016/j.jhydrol.2005.07.032

[5] Lin, G.-F. and Wu, M.-C. (2009) A Hybrid Neural Network Model for Typhoon-Rainfall Forecasting. Journal of Hydrology, 375, 450-458. https://doi.org/10.1016/j.jhydrol.2009.06.047

[6] Kentel, E. (2009) Estimation of River Flow by Artificial Neural Networks and Identification of Input Vectors Susceptible to Producing Unreliable Flow Estimates. Journal of Hydrology, 375, 481-488. https://doi.org/10.1016/j.jhydrol.2009.06.051 
[7] Chua, L.H.C. and Wong, T.S.W. (2010) Improving Event-Based Rainfall-Runoff Modeling Using A Combined Artificial Neural Network-Kinematic Wave Approach. Journal of Hydrology, 390, 92-107. https://doi.org/10.1016/j.jhydrol.2010.06.037

[8] Wu, C.L., Chau, K.W. and Fan, C. (2010) Prediction of Rainfall Time Series Using Modular Artificial Neural Networks Coupled with Data-Preprocessing Techniques. Journal of Hydrology, 389, 146-167. https://doi.org/10.1016/j.jhydrol.2010.05.040

[9] Meledje, N.H., Kouassi, K.L., Alexis, N.Y. and Savané, I. (2013) Probability Distribution of Rainfall in the Bia Watershed: Contribution of Markov Chains. Hydrology in a Changing World: Environmental and Human Dimensions, 363, 379-385.

[10] Coulibaly, P., Anctil, F. and Bobee, B. (2000) Daily Reservoir Inflow Forecasting Using Artificial Neural Networks with Stopped Training Approach. Journal of $\mathrm{Hy}$ drology, 230, 244-257. https://doi.org/10.1016/S0022-1694(00)00214-6

[11] ASCE (2000) Articifial Neural Networks in Hydrology. II: Hydrological Applications. Journal of Hydrologic Engineering, 5, 124-137. https://doi.org/10.1061/(ASCE)1084-0699(2000)5:2(124)

[12] Tricart, J., et al. (1973) Une monographie physique de la Côte-d'Ivoire. Annales de Géographie, 82, 369-372.

[13] Özel, T. and Nadgir, A. (2002) Prediction of Flanck Wear by Using Back Propagation Neural Network Modeling When Cutting Hardened H-13 Steel with Chamfered and Honed CBN Tools. International Journal of Machine Tools \& Manufacture, 42, 287-297. https://doi.org/10.1016/S0890-6955(01)00103-1

[14] Mélèdje, N.H. (2016) Modélisation de la dynamique hydrologique et du flux de sédiments dans le lac du barrage hydroélectrique d'Ayamé1 [Modeling the Hydrological Dynamics and Sediment Flow in the Lake of the Hydroelectric Dam of Ayame1.]. Doctorat unique, Université Nangui Abrogoua, Abidjan.

[15] Kouassi, K.L. (2007) Hydrologie, Transport Solide et Modélisation de la Sédimentation dans les Lacs des Barrages Hydroélectriques de Côte d'Ivoire: Cas du Lac de Taabo [Hydrology, Solid Transport and Modeling of Sedimentation in the Lakes of the Hydropower Dams of Côte d'Ivoire: Case of Lake Taabo.]. Thèse de doctorat, Université d'Abobo-Adjamé, Abidjan.

[16] Oudin, L. (2003) Une formule simple d'évapotranspiration potentielle pour la modélisation pluie-débit à l'échelle d'un bassin versant. [A Simple Formula of Potential Evapotranspiration for the Rainfall-Discharge Modeling at the Scale of a Watershed.] La houille blanche, 6, 8 p.

[17] Zhang, B., Xu, D., Liu, Y., Li, F., Cai, J. and Du, L. (2016) Multi-Scale Evapotranspiration of Summer Maize and the Controlling Meteorological Factors in North China. Agricultural and Forest Meteorology, 216, 1-12.

https://doi.org/10.1016/j.agrformet.2015.09.015

[18] Mouelhi, S. (2003) Vers une chaîne cohérente de modèles pluie-débit conceptuels globaux aux pas de temps pluriannuel, annuel, mensuel et journalier. [Towards a Coherent Chain of Conceptual Rain-Flow Models at Multi-Year, Annual, Monthly and Daily Times.] Thèse de doctorat, Ecole Nationale du Génie Rural des Eaux et des Forêts, Paris.

[19] Koffi, Y.B. (2007) Modélisation pluie-débit en région tropicale humide: Application des réseaux de neurones sur quatre stations hydrométriques du Bandama Blanc (Bada, Marabadiassa, Tortiya et Bou), Nord de la Côte d'Ivoire. [Rainfall-Flow Modeling in the Humid Tropics Region: Application of Neural Networks at Four Bandama Blanc Hydrometric Stations (Bada, Marabadiassa, Tortiya and Bou), 
Northern Côte d'Ivoire.] Thèse de doctorat, Université de Cocody, Abidjan.

[20] Randrianarivony, R.N., Lauret, P., Randriamanantany, Z.A. and Gatina, J.C. (2009) Modélisation du régime annuel des petites rivières en vue d'installation de microcentrales hydroélectriques. [Modeling the Annual Regime of Small Rivers for the Installation of Micro Hydropower Plants.] Afrique Science: Revue Internationale des Sciences et Technologie, 5, $11 \mathrm{p}$. 